\title{
Conifer Seedling Survival in Response to High Surface Temperature Events of Varying Intensity and Duration
}

\author{
Robin Rank ${ }^{1 *}$, Marco Maneta ${ }^{2}$, Philip Higuera ${ }^{3}$, Zachary Holden ${ }^{4}$ and \\ Solomon Dobrowski ${ }^{1}$
}

${ }^{1}$ Forest Landscape Ecology Lab, Department of Forest Management, University of Montana, Misosula, MT, United States, ${ }^{2}$ PaleoEcology and Fire Ecology Lab, Department of Ecosystem and Conservation Sciences, University of Montana, Misosula, MT, United States, ${ }^{3}$ Regional Hydrology Lab, Department of Geosciences, University of Montana, Misosula, MT, United States, ${ }^{4}$ US Forest Service Region 1, Missoula, MT, United States

\section{OPEN ACCESS}

Edited by:

Barry Alan Gardiner,

Institut Européen De La Forêt Cultivée

(IEFC), France

Reviewed by:

Torsten Vor,

University of Göttingen, Germany

María Florencia Urretavizcaya,

Consejo Nacional de Investigaciones

Científicas y Técnicas (CONICET),

Argentina

*Correspondence:

Robin Rank

robin.rank@umontana.edu

Specialty section:

This article was submitted to

Forest Disturbance,

a section of the journal

Frontiers in Forests and Global

Change

Received: 26 June 2021 Accepted: 13 December 2021

Published: 28 January 2022

Citation:

Rank R, Maneta M, Higuera P, Holden Z and Dobrowski S (2022) Conifer Seedling Survival in Response to High Surface Temperature Events of Varying Intensity and Duration.

Front. For. Glob. Change 4:731267. doi: 10.3389/ffgc.2021.731267
Forests face accelerating threats due to increases in the severity and frequency of drought and heat stress associated with climate change. In particular, changing patterns of forest regeneration after disturbance will be important in predicting future forest distribution across the western United States, where patterns of recurring fire and regrowth are important in establishing landscape dynamics. To predict shifting landscape patterns, it will be important to identify environmental boundaries for forest regeneration using environmental variables with clear consequences for seedling survival. Here, we explore soil surface temperature as an environmental variable with direct consequences for seedling survival and forest regeneration potential. We conducted a literature search to identify five previous laboratory experiments, spanning a period of 1924 to 1986, that exposed conifer seedlings to elevated soil surface temperatures for varying durations. We then synthesized the data from these studies to explore the survival of western U.S. conifer species in response to differing surface temperature levels. We found mortality thresholds consistent with previously reported measurements in field and lab studies, but found that as surface temperatures reach these lethal thresholds the duration of exposure matters greatly to survival outcomes. This work leverages an intuitive climate metric with clear consequences for seedling survival as an indicator of forest regeneration potential.

Keywords: seedling survival, surface temperature, heat stress, Bayesian modeling, logistic regression

\section{INTRODUCTION}

Forests play a central role in global water, energy, and biogeochemical cycles, serve as important sources of biodiversity, are the focus of climate change mitigation strategies, and provide essential ecosystem services to communities around the globe (Bonan, 2008; Pan et al., 2013; Anderegg et al., 2015; Bastin et al., 2019). Forests also face accelerating threats due to increases in the severity and frequency of drought and heat stress associated with climate change which are changing forest extent and composition (Allen et al., 2010, 2015). These permanent changes to forested landscapes occur through both mature die-off events (Allen et al., 2010; Coop et al., 2016) and through reductions in forest regeneration after disturbance (Anderson-Teixeira et al., 2013; Savage et al., 2013; Donato et al., 2016). 
Forest regeneration is increasingly garnering the attention of researchers and managers given that seedlings are uniquely sensitive to climate trends and weather extremes. Viewing forest distribution through the lens of regeneration is particularly useful when forests are in disequilibrium with climate, as is the case with long-lived woody vegetation during periods of directional climate change (Bertrand et al., 2016). Mature forest stands, with deeper access to groundwater resources and greater tolerance to high temperature, may persist at a site long after local conditions have passed thresholds suitable for the growth of seedlings, which have smaller thermal and hydrologic niches (Bell et al., 2014; Dobrowski et al., 2015; Bertrand et al., 2016). This disequilibrium will persist until the current cohort dies and is not replaced. Disturbances such as a stand-replacing fire can accelerate this process by killing mature trees (Johnstone et al., 2016). Predicting future changes in forest extent thus necessarily requires an explicit focus on forest regeneration.

Given that disturbances are accelerating mortality, a focus on regeneration will be even more important for predicting future forest distributions in the western United States, where patterns of recurring wildfire and recovery are important in establishing landscape dynamics (Johnstone et al., 2016). These landscapes are expected to experience more frequent and severe fires in the coming decades (Flannigan et al., 2009; Westerling et al., 2011; Littell et al., 2018), which may further accelerate landscape transformations. A growing body of evidence suggests that under directional climate change, post-disturbance landscapes at the drier, hotter edges of current species ranges are becoming unsuitable for regeneration, facilitating conversions from forest to non-forest (Donato et al., 2016; Stevens-Rumann et al., 2018; Walker et al., 2018; Davis et al., 2019; Coop et al., 2020). Predictions of future landscape conversion will require identifying the environmental conditions under which regeneration is possible.

Regeneration after disturbance relies on seedling recruitment, in which viable seeds are dispersed and seedlings successfully establish. Once established, tree seedling survival has been traditionally understood as an interaction between hydraulic stress, temperature stress, carbon starvation, and biotic agent attack (McDowell et al., 2008, 2011). Models of seedling survival, mortality, or recruitment have relied on a variety of environmental predictors, like vapor pressure deficit or soil moisture, to capture some element of the climatologic or hydrologic conditions contributing to seedling growth and survival. Here, we assess soil surface temperature (hereafter, surface temperature) as a predictor of seedling survival.

Surface temperatures are a measurements of the energy balance at the Earth's surface that are governed by net radiation and soil moisture (Jin and Dickinson, 2010; Mildrexler et al., 2011). They can differ substantially from air temperatures measured just centimeters above the ground (Vaartaja, 1949; Silen, 1960; Jin and Dickinson, 2010), and high surface temperatures have been recognized as a direct cause of seedling mortality since the early 20th century (Hartley, 1918). Incoming radiation heats the soil surface, while soil water content increases the thermal heat capacity of the soil. Thus, as soil moisture increases, the same amount of incoming radiation will result in lower heating of the soil surface. Importantly, satellite-based radiometric measures of surface temperature provide continuous spatial coverage, although they can only provide information on surface temperature in unvegetated areas. If surface temperatures can be used to predict seedling survival, it would enable the assessment of forest regeneration potential at multiple spatial scales. In a single, easily retrievable measurement, surface temperature incorporates information about the energy and water balance at a site, providing potentially useful information about seedling viability.

There is reason to suspect that surface temperatures will serve as a reliable predictor of seedling survival. Tree seedlings are extremely sensitive to elevated surface temperatures-first year germinants do not have well-developed bark or access to deep groundwater reserves and are more sensitive to heatinduced lesions and mortality than more established individuals. Heat conducted from soil surrounding the seedling causes irreversible damage to enzymes and proteins in the protoplasm and cell membranes, leading to stem damage and death (Gates, 2012). Thus, at high surface temperatures, small changes in the duration of heat exposure greatly impact seedling survival (Seidel, 1986). These short-term dynamics are experienced by seedlings in the field, where surface temperatures undergo highfrequency variations over hourly to diurnal time scales (Jin and Dickinson, 2010, Supplementary Figure S9). However, field studies of seedling survival do not typically account for these fine temporal dynamics, which limits our understanding of seedling sensitivity to high surface temperatures. While it has long been recognized that the duration of exposure to high surface temperatures impacts survival outcomes (Bates and Roeser, 1924), threshold responses to temperature, sensitivity across species, and the relative importance of exposure duration remains unclear.

Here, we examine seedling tolerances to surface temperature intensity and duration at fine spatio-temporal scales in common conifer species of the western United States. Multiple experiments have measured seedling survival while exposing seedlings to high surface temperatures in controlled environments. However, it remains unclear how conifer species respond when exposed to high surface temperatures, and how this response varies among species. We synthesized the results from past surface temperature exposure experiments and used Bayesian inference to construct a hierarchical generalized linear model to measure the response of western U.S. conifer seedlings to surface temperature intensity and duration, and to quantify the variation in these responses across eight species. We use our model to characterize the environmental boundaries for suitable seedling survival in the western U.S.

\section{METHODS}

\subsection{Data Collection}

We conducted a literature search to gather previously published data relating seedling survival to surface temperature intensity and duration. To be included in this analysis, studies had to expose seedlings to a constant surface temperature for a specified duration, and report seedling survival at sub-hourly 
TABLE 1 | Summary of information from the five studies used in this analysis.

\begin{tabular}{|c|c|c|c|c|c|c|}
\hline Reference & $\begin{array}{l}\text { Number of } \\
\text { observations }\end{array}$ & Heating method & $\begin{array}{l}\text { Seedling age } \\
\text { range (days) }\end{array}$ & $\begin{array}{l}\text { Temperature } \\
\text { range }(\circ \mathrm{C})\end{array}$ & $\begin{array}{l}\text { Exposure duration } \\
\text { range (minutes) }\end{array}$ & Species \\
\hline Baker, 1929 & 10 & Electric Heater & 21 & $48.9-54.5$ & $1-15$ & Pinus radiata \\
\hline Bates and Roeser, 1924 & 106 & Electric heater & $46-90$ & $25.9-56.8$ & $5-128$ & $\begin{array}{l}\text { Pinus ponderosa, Pinus } \\
\text { contorta, Pseudotsuga } \\
\text { menziesii, Picea } \\
\text { engelmannii }\end{array}$ \\
\hline Daubenmire, 1943 & 25 & $\begin{array}{l}\text { Radiant heat lamp } \\
\text { and heating cable }\end{array}$ & 47 & $40-60$ & 360 & $\begin{array}{l}\text { Pinus ponderosa, Pinus } \\
\text { contorta, Pseudotsuga } \\
\text { menziesii, Pinus edulis }\end{array}$ \\
\hline Seidel, 1986 & 192 & Dry water bath & $14 / 28$ & $48.8-62.8$ & $1-300$ & $\begin{array}{l}\text { Pinus ponderosa, } \\
\text { Pseudotsuga menziesii, } \\
\text { Abies grandis, Picea } \\
\text { engelmannii }\end{array}$ \\
\hline Silen, 1960 & 55 & Dry water bath & $7-20$ or $90-95$ & $47.8-66.7$ & $1-610$ & Pseudotsuga menziesii \\
\hline
\end{tabular}

intervals. In addition, studies had to include conifer species found in the western U.S. Ultimately, we found five articles that included the appropriate published data, and they span a period from 1924 to 1986 (Bates and Roeser, 1924; Baker, 1929; Daubenmire, 1943; Silen, 1960; Seidel, 1986). The relationship between seedling survival and surface temperature was captured experimentally by using an external heat source to maintain elevated surface temperatures and measuring seedling survival at specific intervals of exposure. Experimental procedures varied (Table 1), but all took place in a greenhouse or laboratory setting-no publications were found that recorded field data at a fine enough temporal resolution for this analysis. To isolate the effect of surface temperature on seedling survival, these studies maintained well-watered soil throughout their experiments. One study, Daubenmire (1943), repeatedly exposed the same seedlings to higher surface temperatures, allowing for possible seedling hardening. In the rest of the studies, seedlings were only measured once. Data were obtained from tables or figures in published manuscripts: values from tables were directly transcribed, while values from figures were estimated by using a ruler to identify where data points crossed figure axes. Ultimately, we obtained 390 observations of eight different conifer species, with the majority of observations consisting of ponderosa pine (Pinus ponderosa, 84/390), Douglasfir (Pseudotsuga menziesii, 135/390), Engelmann spruce (Picea engelmannii, 80/390), or grand fir (Abies grandis, 48/390) (Figure 1). Here, an observation refers to a population of conifer seedlings subjected to an experimental treatment consisting of a specific surface temperature exposure with a specified duration and intensity. Only one observation exposed seedlings to elevated temperatures for longer than $400 \mathrm{~min}$-this observation was excluded from our dataset when fitting the model.

\subsection{Statistical Model of Seedling Survival}

The experimental data used here come from studies designed in a similar fashion to a clinical trial-a treatment (surface temperature) was applied to a population of seedlings for a known length of time, and survival was measured at varying time intervals. These experiments resulted in right-censored observations, or populations of seedlings that did not experience complete mortality during the period of observation. Because of the structure of these data, we initially explored a survival analysis, a class of statistical models commonly used in clinical studies or studies of mechanical failure which focus on the expected duration of time until an individual experiences some event of interest. We compared the performance of a multi-level Weibull proportional hazards model to a multiple logistic regression more common in tree mortality studies, and found that the multiple logistic regression provided a better fit to our data (Supplementary Results). Logistic models are one of the most widely used techniques in predicting postfire tree mortality, and have been used to represent fire and environmental effects on seedling survival (Woolley et al., 2012).

For this analysis, we constructed a hierarchical multiple logistic regression using Bayesian inference. We calculated seedling survival probability using a generalized linear model where the conditional probability $P$ that a population of seedlings experiences complete mortality $(Y=1)$, given a specific surface temperature value and exposure duration, is represented as

$$
P\left(Y=1 \mid X_{T}, X_{D}\right)=\frac{1}{1+e^{-\left(\left(\beta_{0}+\beta_{4}\right)+\beta_{1} X_{T}+\beta_{2} X_{D}+\beta_{3} X_{T} X_{D}\right)}}
$$

where $X_{T}$ is surface temperature in degrees Celsius, and $X_{D}$ is exposure duration in minutes. The linear function, $\beta_{0}+$ $\beta_{1} X_{T}+\beta_{2} X_{D}+\beta_{3} X_{T} X_{D}$, is the logit link function, where $\beta_{0}$ is an intercept term, $\beta_{1}$ is the surface temperature coefficient, $\beta_{2}$ is the exposure duration coefficient, and $\beta_{3}$ is an interaction term between surface temperature and exposure duration. To determine whether observations from each study demonstrated bias, we included the term $\beta_{4}$, which represents the effect of each study on the model intercept.

This model was written and implemented using the $\mathrm{R}$ package rstanarm (Goodrich et al., 2020), and Bayesian inference was performed using the Hamiltonian Markov Chain Monte Carlo (MCMC) scheme in Rstan (Stan Development Team, 2020). The model was fit using four Markov chains with a 2,000 iteration burn-in period and a 2,000 iteration sampling 


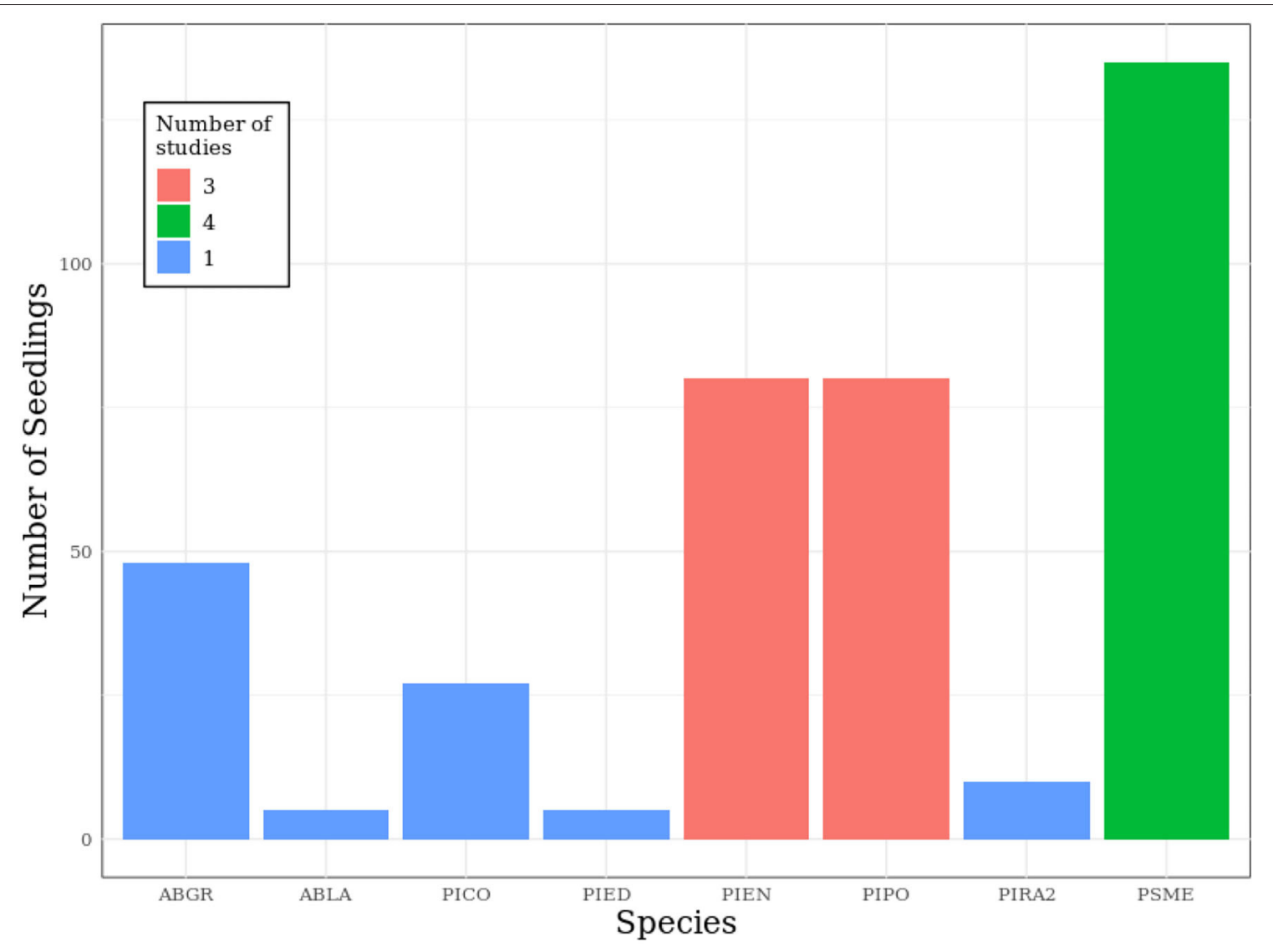

FIGURE 1 | Summary of seedling populations used in each of the studies from the literature search. Most experimental designs included four types of seedlings, with the exception of Baker 1929 and Silen 1960. Species represented in the dataset include Abies grandis (ABGR), Abies lasiocarpa (ABLA), Pinus contorta (PICO), Pinus edulis (PIED), Picea engelmannii (PIEN), Pinus ponderosa (PIPO), Pinus radiata (PIRA2), and Pseudotsuga menziesii (PSME).

period. We evaluated the convergence of Markov chains by visually inspecting plot traces and using Gelman Rubin R-hat statistics (values < 1.1). We used weakly informative priors for all model parameters (normal distribution with mean 0 and standard deviation 2.5), as we had no information on reasonable prior values.

Our model predicts survival for an individual (seedling) that belongs to a group (species). To account for the differences between groups and measure inter-species variation in survival curves, we used a hierarchical prediction framework in estimating the posterior distribution of the intercept parameter, $\beta_{0}$. This hierarchical structure allows us to construct a pooled intercept parameter that informs species-specific intercepts, which are allowed to vary. This makes it possible to estimate model parameters for species with very few observations and evaluate the inter-species variation in modelled survival responses.

\section{RESULTS}

Our model adequately fits observed data as measured by receiver operating curves (ROC) and $k$-fold validation. We constructed ROCs of predicted and observed mortality for 4,000 posterior predictive draws from the model, and the mean area under the curve (AUC) is $0.73 \pm 0.02 S D$ (Figure 2A). Using repeated kfold validation with 10 folds and 20 repetitions, we find that model mean square error (MSE) for the proportion of surviving seedlings is $0.1 \pm 0.03 S D$ and mean absolute error (MAE) is $-0.1 \pm 0.04 S D$ (Figures 2B,C). Model parameters suggest that studies did exert a strong influence over survival outcomes, modifying the model intercept to result in a range of survival probabilities from 0.32 to 1 when surface temperature and exposure duration are held constant at their mean values for each study. While the bias of most studies is similar, (Daubenmire, 1943) accounts for most of the range in these survival outcomes (Supplementary Figure S8), severely overestimating survival probabilities at high temperatures. For the rest of the paper, we present model results using the bias correction for (Seidel, 1986) and ignore offsets from all other studies, as Seidel (1986) accounts for the greatest percentage of observations (49\%). In addition, this bias correction (2.2) is close to the averaged corrections of all studies (3.8), so will not bias the presentation of survival outcomes.

When plotted against surface temperature as measured in degrees Celsius, survival probabilities using mean model parameters from posterior distributions show predicted survival 

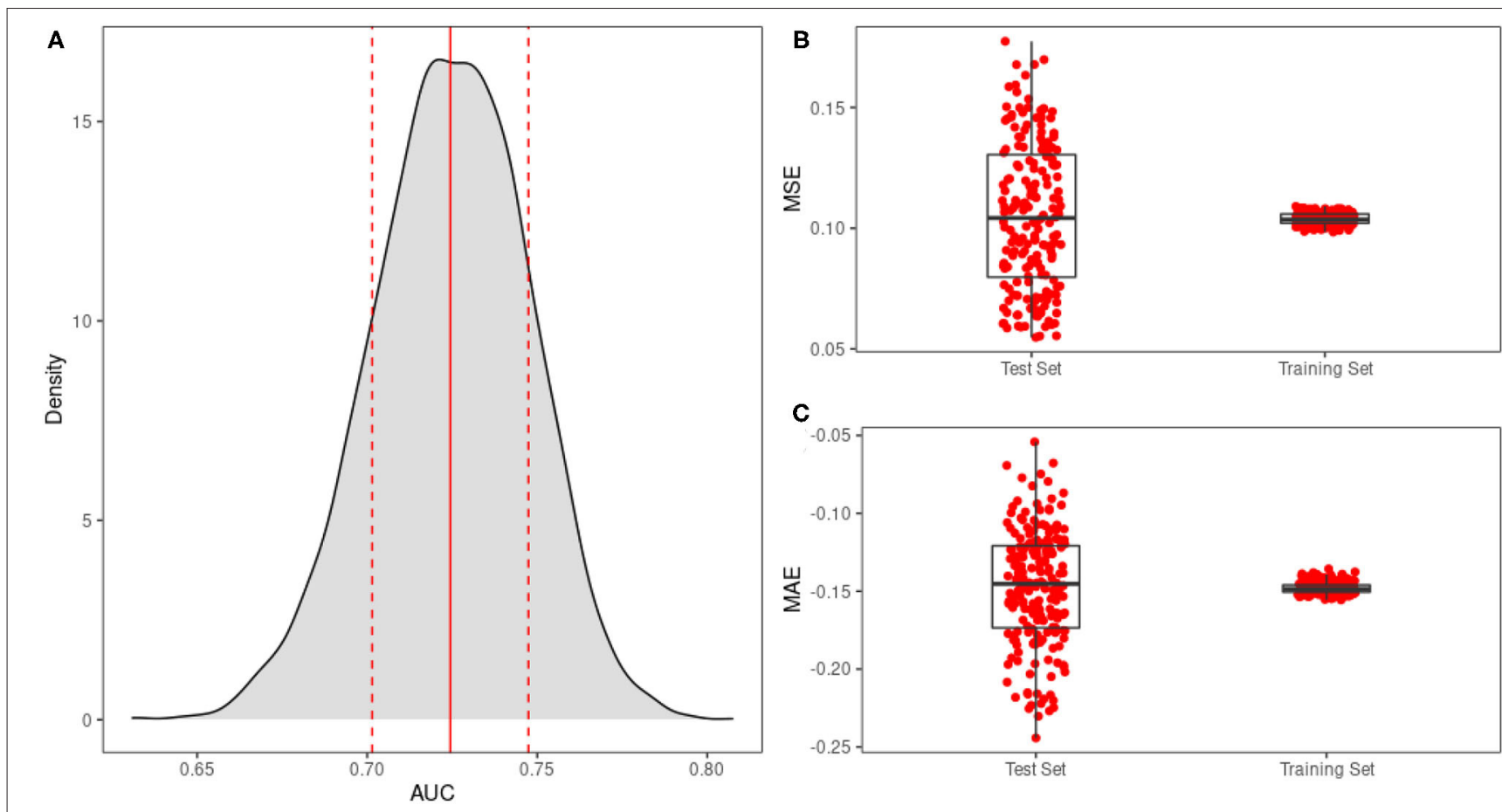

FIGURE 2 | (A) The distribution of AUC values for 4,000 draws from the posterior distribution, where the solid line represents mean AUC, and dashed lines represent 1 standard deviation. Also shown are the distributions of (B) mean square error (MSE) values and (C) mean absolute error (MAE) values from repeated $k$-fold validation.

beginning to decrease past $40^{\circ} \mathrm{C}$ (Figure 3). These survival curves are moderated by exposure time. At the low and high end of surface temperatures represented in this study, seedling survival does not vary greatly over the duration of exposure. However, between approximately $45^{\circ} \mathrm{C}$ and $60^{\circ} \mathrm{C}$, the duration of exposure greatly modifies predicted survival outcomes (Figure 3). Ultimately, this means that as surface temperatures approach these threshold values, there is a greater range of modeled survival outcomes depending on the exposure duration, until surface temperatures reach extreme values at or above $60^{\circ} \mathrm{C}$. If the exposure duration is unknown at these transitional surface temperatures, we have lower confidence in our predictions of survival probability.

When using modeled outcomes to investigate common population-level mortality thresholds, a few patterns emerge. Firstly, there is very little inter-species variation in surface temperatures required to meet progressively higher mortality thresholds in any of the species represented (Figure 3). When surface temperature and exposure duration are held constant at their mean values in our data set, species-level intercept values predict differences in survival probabilities from 0.11 to 0.17 over all eight species. In addition, as surface temperature increases, the duration of heat exposure required to cross lethal dosage thresholds for 50\% (LD50), 75\% (LD75), and $90 \%$ (LD90) mortality is reduced (Figure 4). However, the curves that correspond to these three lethal dosage thresholds begin to converge on a common duration value as surface temperature increases (Figure 4). This experimental duration converges on $0 \mathrm{~min}$ of exposure for each species. As surface temperature increases, exposure duration matters less to survival outcomes (Figure 4).

\section{DISCUSSION}

Field studies of post-disturbance seedling survival rarely measure high-frequency dynamics in surface temperature, and lab or greenhouse studies of this phenomenon have not-until nowbeen synthesized to construct a more complete picture of conifer seedling sensitivity to elevated surface temperatures. Fine-scale surface temperature variability, in space and time, is mostly due to variation in solar insolation driven by changes in cloud cover. Surface temperatures can vary at fine temporal scales in the hottest parts of the day (Supplementary Figure S8), and the research presented here suggests that as surface temperatures reach lethal temperatures, those small-scale changes in duration have biologically meaningful impacts on survival (Figure 3). For example, our model predicts that at a surface temperature of $55^{\circ} \mathrm{C}$, a Douglas fir seedling will cross the $50 \%$ mortality threshold, with estimated probability of death increasing from $49 \%$ to $51 \%$, in $5 \mathrm{~min}$. A further $30 \mathrm{~min}$ of exposure will increase the probability of mortality to $60 \%$. When we broaden our scope, the convergence of these $50 \%$ lethal dosage thresholds on common exposure duration values (Figure 4) may indicate a common limit of tolerance to thermal damage across species. In the well-watered conditions maintained in these studies, a common temperature sensitivity across species is not surprising given that all plants share similar cellular machinery. However, these tree species would exhibit much greater variability in their 

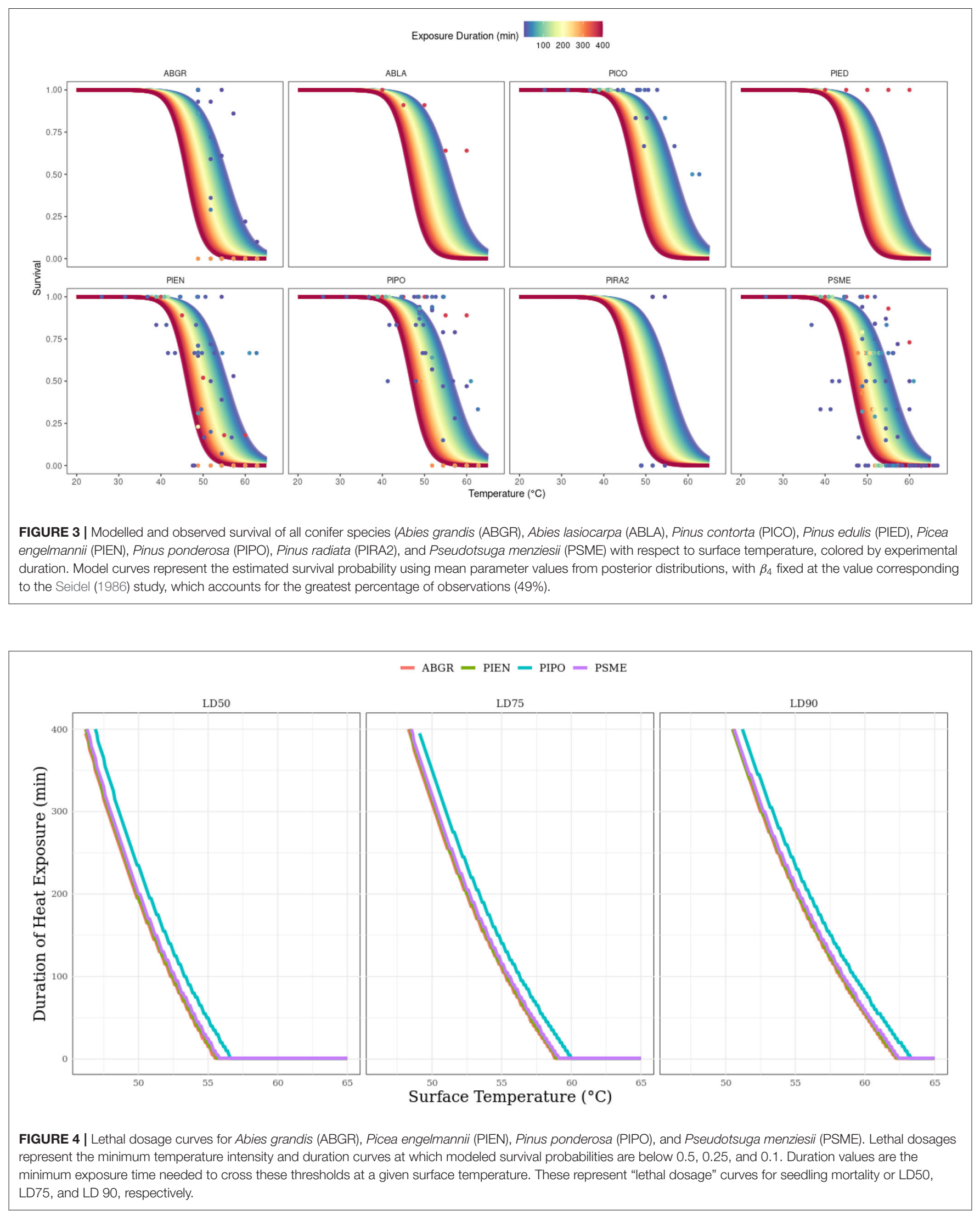
temperature response in-situ, where water and heat stress are coupled (McDowell et al., 2011).

Previous research has shown that surface temperature measurements from $52^{\circ} \mathrm{C}$ to $66^{\circ} \mathrm{C}$ signify the onset of seedling mortality (Helgerson, 1989). Using the model constructed here, if we plot the surface temperature vs. duration curves that correspond to $75 \%$ seedling mortality, it is clear that the concept of a lethal temperature strongly depends on the duration of exposure (Figure 3). For example, a lethal surface temperature could be as low as $52^{\circ} \mathrm{C}$ or as high as $58^{\circ} \mathrm{C}$. This range of values is still consistent with previously reported temperature thresholds, so we can assume that surface temperature on its own still contains valuable information about the potential for seedling mortality. However, our synthesis quantifies the extent to which the duration of heat exposure also impacts seedling mortality across conifer species (Bates and Roeser, 1924; Baker, 1929; Daubenmire, 1943; Silen, 1960; Seidel, 1986; Helgerson, 1989; Kolb and Robberecht, 1996). Accordingly, information on surface temperature exposure duration may improve predictions of forest regeneration potential.

One of the most important insights of this model is that small changes in the duration of heat exposure matter more as surface temperature reaches lethal temperatures, until it reaches about $60^{\circ} \mathrm{C}$ (Figure 3). We can again return to our hypothetical Douglas-fir seedling. According to our model, at a surface temperature of $50^{\circ} \mathrm{C}$, a Douglas-fir seedling requires $200 \mathrm{~min}$ of exposure to cross the $50 \%$ mortality threshold. At $55^{\circ} \mathrm{C}$, that seedling would only require $25 \mathrm{~min}$ of exposure, while only $1 \mathrm{~min}$ of exposure to a surface temperature of $60^{\circ} \mathrm{C}$ is needed to pass this $50 \%$ mortality threshold. The choice of temperature values here is arbitrary but illustrative of the larger pattern in model outcomes (Figure 3). Surface temperatures in these ranges are not uncommon during summer in many temperate regions. Indeed, large areas of the western U.S. - most of the southwest and the semiarid interior stretching northreach yearly maximum surface temperatures at or above $50^{\circ} \mathrm{C}$ (Mildrexler et al., 2011). Even high-elevation locations within the western US can reach lethal temperatures. In one area of Rocky Mountain National Park dominated by lodgepole pine, subalpine fir, and Douglas-fir, surface temperature values measured by the National Ecological Observatory Network (NEON) regularly exceeded $60^{\circ} \mathrm{C}$ in the summer (Supplementary Figure S10).

Surface temperature varies dramatically with land cover, soil moisture content, evapotranspiration rates, albedo, and other environmental factors (Jin and Dickinson, 2010; Mildrexler et al., 2011; Li et al., 2015, 2016). Because surface temperature is tightly coupled to the surface energy balance of the Earth, the highest surface temperatures are typically found in areas of low canopy cover where soil is exposed to high levels of solar radiation. These conditions are common in semi-arid environments and in a range of other ecosystems after stand replacing disturbances such as fire. Recent evidence suggests that measurable increases in surface temperature follow fire-induced forest loss across the globe (Liu et al., 2019). As warmer, drier conditions persist in the western U.S. along with a projected increase in the frequency and severity of wildfire (Flannigan et al., 2009; Westerling et al., 2011; Littell et al., 2018), surface temperatures may become an increasingly important limiting factor in regeneration success
(Bell et al., 2014; Enright et al., 2015; Hankin et al., 2019), and sites that currently experience temperatures suitable for post-fire recruitment may be too warm to do so in the future (Davis et al., 2019).

This work represents an important step toward identifying inter-species variation in the environmental boundaries for forest regeneration based on surface temperature. However, much remains unknown. Only four species-ponderosa pine, Douglas-fir, Engelmann spruce, and grand fir-dominate our experimental data. These species occur in many of the mixed-conifer forests of the western U.S., and just twoponderosa pine and Douglas-fir-are the most widespread and commercially important conifer species in the western U.S. Their representation in this dataset makes it more informative about West-wide forest response to elevated surface temperatures, even though species that occur in more xeric environments, like Piñon pine, represent a small proportion of total observations. While seedling response to surface temperature showed very little interspecies variation (Supplementary Figure S8), the exclusion of water stress in this analysis limits our ability to make inference under in-situ conditions due to coupled water and heat stress. Although the latter explanation seems plausible, we fitted a statistical model with a predefined distribution that has very few parameters and should be robust to sparse data. While this model is a promising start, it lacks representations of more xeric conifer species, and more research is required to determine if conifer species across the western U.S. have similar tolerances with respect to elevated surface temperatures.

There are other limits of this study that point to promising directions for future research. First, the effects of seedling hardening are not accounted for here. Only one study repeatedly exposed the same seedlings to higher surface temperatures, allowing for seedling hardening to possibly impact survival results (Daubenmire, 1943). Those observations account for 6\% of the total data, and we do not account for that experimental hardening in our analyses. This may impact the utility of lab or greenhouse studies compared to field studies, as most seeds germinate in April and May and are subjected to gradually increasing surface temperatures as the soil dries. In addition, all studies maintained well-watered soil during their experiments, so the survival curves presented here may not transfer to field settings where soil moisture is limiting and seedlings may not be able to avoid heat damage through transpirational cooling (Kolb and Robberecht, 1996).

Other limitations of these data are technical, and stem from the age of this body of work. Surface temperatures were measured with thermocouples or thermometer bulbs buried in the soil surface, which are less accurate methods than a modern thermal imaging camera. This also makes it hard to determine whether surface temperatures remained constant throughout the duration of experiments, as variations in measured temperature resulting from the error associated with these devices could obscure actual changes in surface temperature. Our model suggests that this may be the case in Daubenmire (1943), which is associated with much higher survival outcomes at extreme temperatures than any other study (Supplementary Figure S8). These technical limitations point to a need for experiments using more accurate methods of measurement on a wider range of species, in both 
the lab and field. The model presented here can inform future research, without which the general response of western U.S. conifers to changes in surface temperature intensity and duration remains unclear.

Overall, this research helps elucidate the mechanisms that may be responsible for the susceptibility of forests to regeneration failure at drier, lower-elevation limits of their current ranges, driving changes in forest extent and composition across the western U.S. (Dobrowski et al., 2015; Donato et al., 2016; Stevens-Rumann et al., 2018; Davis et al., 2019; Simeone et al., 2019; Wolf et al., 2021). Lethal surface temperatures may occur more frequently in drier, hotter post-fire landscapes in the coming decades (Liu et al., 2019), where surface temperature can serve as a valuable source of information when predicting forest regeneration. Surface temperature is a valuable indicator of the risk of regeneration failure as it has well-understood consequences for seedling survival, and this work suggests there is little inter-species variation in seedling response to surface temperature. Moreover, surface temperature measurements by Earth-observing satellites can be incorporated into ongoing monitoring frameworks and mapped easily across landscapes. Going forward, soil surface temperatures have great potential as an intuitive metric of mortality risk for seedlings under a warming climate.

\section{REFERENCES}

Allen, C. D., Breshears, D. D., and McDowell, N. G. (2015). On underestimation of global vulnerability to tree mortality and forest die-off from hotter drought in the anthropocene. Ecosphere 6, art129. doi: 10.1890/ES15-00203.1

Allen, C. D., Macalady, A. K., Chenchouni, H., Bachelet, D., McDowell, N., Vennetier, M., et al. (2010). A global overview of drought and heat-induced tree mortality reveals emerging climate change risks for forests. Forest Ecol. Manag. 259, 660-684. doi: 10.1016/j.foreco.2009.09.001

Anderegg, W. R., Flint, A., Huang, C.-y., Flint, L., Berry, J. A., Davis, F. W., et al. (2015). Tree mortality predicted from drought-induced vascular damage. Nat. Geosci. 8, 367-371. doi: 10.1038/NGEO2400

Anderson-Teixeira, K. J., Miller, A. D., Mohan, J. E., Hudiburg, T. W., Duval, B. D., and DeLucia, E. H. (2013). Altered dynamics of forest recovery under a changing climate. Glob. Change Biol. 19, 2001-2021. doi: 10.1111/gcb.12194

Baker, F. S. (1929). Effect of excessively high temperatures on coniferous reproduction. J. Forestry 27, 949-975. doi: 10.1093/jof/27.8.949

Bastin, J.-F., Finegold, Y., Garcia, C., Mollicone, D., Rezende, M., Routh, D., et al. (2019). The global tree restoration potential. Science 365, 76-79. doi: $10.1126 /$ science.aax0848

Bates, C. G., and Roeser, J. (1924). Relative Resistance of Tree Seedlings to Excessive Heat. Number 1263, US Department of Agriculture, Washington, DC.

Bell, D. M., Bradford, J. B., and Lauenroth, W. K. (2014). Early indicators of change: divergent climate envelopes between tree life stages imply range shifts in the western u nited s tates. Glob. Ecol. Biogeography 23, 168-180. doi: 10.1111 /geb.12109

Bertrand, R., Riofrio-Dillon, G., Lenoir, J., Drapier, J., De Ruffray, P., Gégout, J.-C., et al. (2016). Ecological constraints increase the climatic debt in forests. Nat. Commun. 7:12643. doi: $10.1038 /$ ncomms 12643

Bonan, G. B. (2008). Forests and climate change: forcings, feedbacks, and the climate benefits of forests. Science 320, 1444-1449. doi: 10.1126/science.1155121

Coop, J. D., Parks, S. A., McClernan, S. R., and Holsinger, L. M. (2016). Influences of prior wildfires on vegetation response to subsequent fire in a reburned southwestern landscape. Ecol. Appl. 26, 346-354. doi: 10.1890/15-0775

\section{DATA AVAILABILITY STATEMENT}

Publicly available datasets were analyzed in this study. This data can be found at: https://github.com/rcdixon/Conifer-SeedlingSurvival.

\section{AUTHOR CONTRIBUTIONS}

RR and SD conceived the study. RR collected and analyzed the data and led the writing of the manuscript. PH, MM, $\mathrm{ZH}$, and SD participated in data interpretation and revised the manuscript. All authors contributed to the article and approved the submitted version.

\section{FUNDING}

Funding for this research provided by the National Aeronautics and Space Administration, Grant \#80NSSC19K00181.

\section{SUPPLEMENTARY MATERIAL}

The Supplementary Material for this article can be found online at: https://www.frontiersin.org/articles/10.3389/ffgc.2021. 731267/full\#supplementary-material

Coop, J. D., Parks, S. A., Stevens-Rumann, C. S., Crausbay, S. D., Higuera, P. E., Hurteau, M. D., et al. (2020). Wildfire-driven forest conversion in Western North American Landscapes. BioScience 70, 659-673. doi: 10.1093/biosci/biaa061

Daubenmire, R. (1943). Soil temperature versus drought as a factor determining lower altitudinal limits of trees in the rocky mountains. Botan. Gazette 105, $1-13$.

Davis, K. T., Dobrowski, S. Z., Higuera, P. E., Holden, Z. A., Veblen, T. T., Rother, M. T., et al. (2019). Wildfires and climate change push low-elevation forests across a critical climate threshold for tree regeneration. Proc. Natl. Acad. Sci. 116, 6193-6198. doi: 10.1073/pnas.1815107116

Dobrowski, S. Z., Swanson, A. K., Abatzoglou, J. T., Holden, Z. A., Safford, H. D., Schwartz, M. K., et al. (2015). Forest structure and species traits mediate projected recruitment declines in western us tree species. Glob. Ecol. Biogeography 24, 917-927. doi: 10.1111/geb.12302

Donato, D. C., Harvey, B. J., and Turner, M. G. (2016). Regeneration of montane forests 24 years after the 1988 yellowstone fires: A fire-catalyzed shift in lower treelines? Ecosphere 7:e01410. doi: 10.1002/ecs2.1410

Enright, N. J., Fontaine, J. B., Bowman, D. M., Bradstock, R. A., and Williams, R. J. (2015). Interval squeeze: altered fire regimes and demographic responses interact to threaten woody species persistence as climate changes. Front. Ecol. Environ. 13, 265-272. doi: 10.1890/140231

Flannigan, M. D., Krawchuk, M. A., de Groot, W. J., Wotton, B. M., and Gowman, L. M. (2009). Implications of changing climate for global wildland fire. Int. J. Wildland Fire 18, 483-507. doi: 10.1071/WF08187

Gates, D. M. (2012). Biophysical Ecology. New York, NY: Courier Corporation.

Goodrich, B., Gabry, J., Ali, I., and Brilleman, S. (2020). rstanarm: Bayesian applied regression modeling via Stan. $R$ Package Version 2.19.3.

Hankin, L. E., Higuera, P. E., Davis, K. T., and Dobrowski, S. Z. (2019). Impacts of growing-season climate on tree growth and post-fire regeneration in ponderosa pine and douglas-fir forests. Ecosphere 10:e02679. doi: 10.1002/ecs2.2679

Hartley, C. (1918). Stem Lesions Caused by Excessive Heat. Washington, DC: US Government Printing Office.

Helgerson, O. T. (1989). Heat damage in tree seedlings and its prevention. New Forests 3, 333-358. doi: 10.1007/BF00030044 
Jin, M. and Dickinson, R. E. (2010). Land surface skin temperature climatology: Benefitting from the strengths of satellite observations. Environ. Res. Lett. 5:044004. doi: 10.1088/1748-9326/5/4/044004

Johnstone, J. F., Allen, C. D., Franklin, J. F., Frelich, L. E., Harvey, B. J., Higuera, P. E., et al. (2016). Changing disturbance regimes, ecological memory, and forest resilience. Front. Ecol. Environ. 14:369-378. doi: 10.1002/fee.1311

Kolb, P. F., and Robberecht, R. (1996). High temperature and drought stress effects on survival of pinus ponderosa seedlings. Tree Physiol. 16, 665-672. doi: 10.1093/treephys/16.8.665

Li, Y., Zhao, M., Mildrexler, D. J., Motesharrei, S., Mu, Q., Kalnay, E., et al. (2016). Potential and actual impacts of deforestation and afforestation on land surface temperature. J. Geophys. Res. Atmospheres 121, 14-372. doi: 10.1002/2016JD024969

Li, Y., Zhao, M., Motesharrei, S., Mu, Q., Kalnay, E., and Li, S. (2015). Local cooling and warming effects of forests based on satellite observations. Nat. Commun. 6, 1-8. doi: 10.1038/ncomms7603

Littell, J. S., McKenzie, D., Wan, H. Y., and Cushman, S. A. (2018). Climate change and future wildfire in the western united states: an ecological approach to nonstationarity. Earth's Future 6, 1097-1111. doi: 10.1029/2018EF000878

Liu, Z., Ballantyne, A. P., and Cooper, L. A. (2019). Biophysical feedback of global forest fires on surface temperature. Nat. Commun. 10, 1-9. doi: 10.1038/s41467-018-08237-z

McDowell, N., Beerling, D., Breshears, D., Fisher, R., Raffa, K., and Stitt, M. (2011). The interdependence of mechanisms underlying climate-driven vegetation mortality. Trends Ecol. Evol. 26, 523-532. doi: 10.1016/j.tree.2011.06.003

McDowell, N., Pockman, W. T., Allen, C. D., Breshears, D. D., Cobb, N., Kolb, T., et al. (2008). Mechanisms of plant survival and mortality during drought: why do some plants survive while others succumb to drought? New Phytol. 178, 719-739. doi: 10.1111/j.1469-8137.2008.02436.x

Mildrexler, D. J., Zhao, M., and Running, S. W. (2011). A global comparison between station air temperatures and modis land surface temperatures reveals the cooling role of forests. J. Geophys. Res. Biogeosci. 116. doi: 10.1029/2010JG001486

Pan, Y., Birdsey, R. A., Phillips, O. L., and Jackson, R. B. (2013). The structure, distribution, and biomass of the world's forests. Ann. Rev. Ecol. Evol. Systematics 44, 593-622. doi: 10.1146/annurev-ecolsys-110512-135914

Savage, M., Mast, J. N., and Feddema, J. J. (2013). Double whammy: high-severity fire and drought in ponderosa pine forests of the southwest. Can. J. Forest Res. 43, 570-583. doi: 10.1139/cjfr-20120404

Seidel, K. (1986). Tolerance of seedlings of ponderosa pine. douglas-fir, grand fir, and engelmann spruce for high temperatures. Northwest Sci. 60.

Silen, R. R. (1960). Lethal Surface Temperatures and Their Interpretation for Douglas-Fir (Master's thesis). Oregon State College, Corvallis, OR.
Simeone, C., Maneta, M. P., Holden, Z. A., Sapes, G., Sala, A., and Dobrowski, S. Z. (2019). Coupled ecohydrology and plant hydraulics modeling predicts ponderosa pine seedling mortality and lower treeline in the us northern rocky mountains. New Phytologist 221, 1814-1830. doi: 10.1111/nph.15499

Stan Development Team (2020). RStan: the R interface to Stan. R Package Version 2.19.3.

Stevens-Rumann, C. S., Kemp, K. B., Higuera, P. E., Harvey, B. J., Rother, M. T., Donato, D. C., et al. (2018). Evidence for declining forest resilience to wildfires under climate change. Ecol. Lett. 21, 243-252. doi: 10.1111/ele.12889

Vaartaja, O. (1949). High surface soil temperatures on methods of investigation, and thermocouple observations on a wooded heath in the south of finland. Oikos 1, 6-28. doi: 10.2307/3565034

Walker, R. B., Coop, J. D., Parks, S. A., and Trader, L. (2018). Fire regimes approaching historic norms reduce wildfire-facilitated conversion from forest to non-forest. Ecosphere 9:e02182. doi: 10.1002/ecs2.2182

Westerling, A. L., Turner, M. G., Smithwick, E. A. H., Romme, W. H., and Ryan, M. G. (2011). Continued warming could transform greater yellowstone fire regimes by mid-21st century. Proc. Natl. Acad. Sci. 108, 13165-13170. doi: 10.1073/pnas.1110199108

Wolf, K. D., Higuera, P. E., Davis, K. T., and Dobrowski, S. D. (2021). Wildfire impacts on forest microclimate vary with biophysical context. Ecosphere 13. doi: $10.1002 /$ ecs 2.3467

Woolley, T., Shaw, D. C., Ganio, L. M., and Fitzgerald, S. (2012). A review of logistic regression models used to predict post-fire tree mortality of western north american conifers. Int. J. Wildland Fire 21, 1-35. doi: 10.1071/WF09039

Conflict of Interest: The authors declare that the research was conducted in the absence of any commercial or financial relationships that could be construed as a potential conflict of interest.

Publisher's Note: All claims expressed in this article are solely those of the authors and do not necessarily represent those of their affiliated organizations, or those of the publisher, the editors and the reviewers. Any product that may be evaluated in this article, or claim that may be made by its manufacturer, is not guaranteed or endorsed by the publisher.

Copyright (C) 2022 Rank, Maneta, Higuera, Holden and Dobrowski. This is an openaccess article distributed under the terms of the Creative Commons Attribution License (CC BY). The use, distribution or reproduction in other forums is permitted, provided the original author(s) and the copyright owner(s) are credited and that the original publication in this journal is cited, in accordance with accepted academic practice. No use, distribution or reproduction is permitted which does not comply with these terms. 